\title{
The moderating effect of exposure to robbery on the relationship between post-traumatic stress and job satisfaction
}

\author{
Francesco MONTANI ${ }^{1}$, Valentina SOMMOVIGO ${ }^{2 *}$, Ilaria SETTI $^{2}$, \\ Gabriele GIORGI ${ }^{3}$ and Piergiorgio ARGENTERO ${ }^{2}$
}

\author{
${ }^{1}$ International University of Monaco, Monaco \\ ${ }^{2}$ Department of Brain and Behavioural Sciences, Unit of Applied Psychology, University of Pavia, Italy \\ ${ }^{3}$ Department of Psychology, European University, Italy
}

Received June 11, 2019 and accepted January 16, 2020

Published online in J-STAGE January 25, 2020

\begin{abstract}
Research has disregarded the boundary conditions of the effects of post-traumatic stress symptoms (PTSS) at work. Addressing this issue, the present study examines the moderating impact of the (shared vs. isolated) exposure to robbery on the relationship between PTSS and employee job satisfaction. Drawing on the conservation of resources theory, we argue that PTSS would positively affect employee job satisfaction when the robbery is experienced collectively. To test our predictions, we conducted a two-wave study — with a lag of two months between measurements - on 140 employees from a national bank in Italy. Results from hierarchical regression analyses supported our prediction: the exposure to robbery moderated the relationship between PTSS and job satisfaction. While within the "isolated exposure" group the job satisfaction score was higher among less symptomatic victims, within the "shared exposure" group those with high PTSS reported higher job satisfaction levels than those with low PTSS. We discuss the implications of these findings for theory and practice.
\end{abstract}

Key words: Post-traumatic stress, Job satisfaction, Exposure to robbery

\section{Introduction}

Bank robberies represent a serious concern worldwide. In Italy, bank robberies were more than 772 in 2015 , representing $60 \%$ of total attacks ${ }^{1}$. Robberies are considered potentially traumatic workplace events (PTEs) because they are unexpected life-threatening events occurring in the course of someone's work ${ }^{2)}$. Exposure to bank robberies may engender numerous mental health

*To whom correspondence should be addressed.

E-mail: valentina.sommovigo@unipv.it

(C)2020 National Institute of Occupational Safety and Health problems ${ }^{3)}$. Among these, attention should be given to post-traumatic stress symptoms (PTSS) that are: intrusion (i.e., re-experiencing the trauma through distressing dreams, flashbacks, feelings), avoidance (i.e., avoiding feelings, thoughts and other reminders of the event) and hyper-arousal (i.e., hyper-vigilance, sleep disturbance, irritability, poor concentration $)^{4)}$. In general, a minority of robbery victims is likely to manifest symptoms of enough severity and duration to comply with criteria for diagnosis of a mental disorder (e.g., post-traumatic stress disorder ${ }^{1}$ ), with the majority suffering from one or more stress symptoms during the first days, weeks and months. However, even normal symptoms (e.g., anxiety, depressive feelings, 
somatic problems) may undermine work capabilities. Re-experiencing and arousal symptoms indeed result in poor concentration and difficulties to meet work-related demands ${ }^{5}$. Moreover, the work environment may become a reminder of the critical event ${ }^{6}$, so that employees may become reluctant to return to their job ${ }^{3)}$. Additional, disruptive consequences of PTSS include sick leave, missed deadlines, and increased accidents ${ }^{3,7)}$. Thus, it has been estimated that in 2010 PTSS across Europe costed 8.4 billion euros in terms of healthcare expenses ${ }^{8}$.

Nevertheless, positive results may follow PTEs and, in some cases, co-occur with PTSS ${ }^{9)}$. Post-traumatic growth (PTG) is the experience of positive change associated with the struggle with stressful situations or traumas ${ }^{10)}$. PTG can be described as a cognitive adaptation process which makes victims able to positively reinterpret their trauma, become more aware of their strengths and develop new coping strategies to face difficulties ${ }^{11)}$.

Literature on trauma suggests that sharing traumatic experiences with other members instills positive group processes $^{12)}$, which have been considered key spurs of PTG. Unfortunately, empirical research testing these assumptions is relatively underdeveloped, thereby limiting significantly our understanding of the effects of PTSS on PTG and the role played by shared traumatic experiences in enabling improved functioning among victims. On the one hand, this study aims to analyze the effects of PTSS following bank robberies on PTG (highlighted as job satisfaction). On the other hand, this study aims to clarify under which circumstances the effects of PTSS on job satisfaction would vary, by investigating whether and how different exposure conditions (i.e., shared vs isolated exposure) would buffer the relationship between PTSS and job satisfaction ${ }^{2}$. Drawing on conservation of resources theory ${ }^{15)}$, we contend that when the exposure to a robbery is collectively shared, victims affected by PTSS will be enabled to access group resources (e.g., social support, group identification) that may promote a greater PTG measured in terms of job satisfaction.

By testing this prediction, this study significantly contributes to the post-traumatic stress literature in two ways. First, while prior research in this area has mostly focused on the negative consequences of PTSS at work, our investigation discloses for the first time whether and under what conditions PTEs can result in improved psychological functioning despite the development of PTSS, thus helping build new theoretical perspectives on the positive outcomes of work-related PTEs. Second, we highlight the relevance of understanding how the collective exposure to the trauma can shape the effects of PTSS on work-related outcomes. This is crucial to formulate preventive measures and tailored interventions that help victims maintain an optimal functioning at work, even in the face of PTEs.

COR theory ${ }^{16,17)}$ is one of the predominant theories used to explain traumatic stress. COR theory proposes that individuals strive to gain and preserve resources (i.e., things that centrally value), which play a major role in determining the way people deal with trauma. Robberies represent stressful events that may seriously impair psychological functioning ${ }^{16,17)}$ since they constitute either a threat to - or an actual loss of - one's working conditions (e.g., personal safety at work ${ }^{18,19)}$. These latter constitute one of the fundamental resources identified by COR theory ${ }^{16,17)}$, together with objects (e.g., tangible benefits), personal characteristics (e.g., resilience), conditions (e.g., safety at work) and energies (e.g., efforts) ${ }^{17)}$. Under periods of traumatic stress, in attempting to cope with the consequences of the trauma, individuals need to invest further resources. If victims are not successful in doing so, they may further aggravate their losses, generating an escalating spiral of losses. Although resource losses are more impactful than equivalent resource gains in predicting $\operatorname{PTSS}^{20)}$, resource gains can serve a buffering function in the face of resource loss ${ }^{21,22)}$. Based on these principles, COR theory ${ }^{16,17)}$ states that the interaction between losses and gains predicts individual responses to PTEs, so that individuals with more resources are better positioned for resource gains and less vulnerable to resource loss ${ }^{17)}$. Importantly, some conditions can provide individuals with opportunities to access resources (e.g., protection against resource loss) that facilitate resource gains (i.e., resource caravan passageways ${ }^{23)}$. Therefore, under favourable circumstances, individuals affected by PTSS can mobilize and acquire new resources, restore their resource pools,

\footnotetext{
${ }^{1}$ To diagnosis PTSD ${ }^{4}$ the following criteria should be met: the person was directly or indirectly exposed to a PTE (Criterion A) and experienced at least one intrusion symptom (Criterion B), one avoidance symptom (Criterion C), two symptoms of negative alterations in cognitions and mood (Criterion D), alterations in arousal and reactivity (Criterion E). Symptoms should last for more than one month (Criterion F), create functional impairment (Criterion $\mathrm{G}$ ) and be not due to medications, substance use or other illnesses (Criterion $\mathrm{H}$ ).

${ }^{2}$ We chose to focus on job satisfaction since it represents a key indicator of psychological functioning at work ${ }^{13)}$ that has been shown to be impaired by distress ${ }^{14)}$ and PTSS $^{15}$ in the context of bank robberies.
} 
offset the conditions that created resource loss and improve their psychological functioning by adopting effective conservation strategies following stressful situations ${ }^{16,24)}$. In this view, PTEs with subsequent PTSS might represent an opportunity for individuals affected to shift their attentional focus towards the possible future gains that might be obtained from the trauma ${ }^{10)}$, ascribe a positive meaning to the traumatic experience, and reappraise more favourably the environment in which the trauma occurred. As a result, they undergo a positive transformation beyond the "previous level of adaptation, psychological functioning, or life awareness" "25).

PTG manifests in the acquisition of important valued resources, including greater appreciation of life, increased sense of personal strength, identification of new possibilities, positive spiritual change and improved interpersonal relationships, all of which are conducive to a more adaptive psychological functioning ${ }^{10)}$. Although the relationship between PTSS and PTG remains unclear ${ }^{26)}$, positive psychological changes following a trauma have been identified among a broad range of victims ${ }^{27-29)}$. Thus, taken together, COR theory ${ }^{16,17)}$ and the post-traumatic stress literature suggest that: a) employees affected by PTSS might experience PTG; and b) such a positive transformation is contingent upon the possibility for the victims to reinvest their available energetic resources towards a cognitive reappraisal of the meaning attributed to the traumatic event.

Furthermore, as suggested by the COR theory ${ }^{16,17)}$, the possibility to harness other types of resources becomes essential to gain new resources and, thereby, enable the victims affected by PTSS to experience a more positive psychological functioning ${ }^{16)}$. Accordingly, the loss of resources derived from robbery exposure might be compensated by a greater investment in other work-related resources that, by allowing employees to cognitively reappraise the trauma, would foster PTG. With regard to this, post-traumatic stress research indicates that when a traumatic event is shared with other people, rather than experienced individually, then subjects are more likely to benefit from greater social support and manifest increased group identification, all factors which have been empirically associated with $\mathrm{PTG}^{30-33)}$. Indeed, the shared nature of the trauma can contribute to create and sustain a sense of groupness and feelings of similarity, thus enhancing stronger relationships and solidarity among victims, who can feel a sense of shared victimhood ${ }^{32,34,35)}$.

When a traumatic event is experienced collectively, the employees affected by PTSS will be more likely to access group-related resources (e.g., social support, group cohesion $^{36)}$ ) which would enhance victims' self-efficacy ${ }^{37}$ and facilitate communal coping processes (e.g., through emotional expression) ${ }^{38)}$. These latter are characterized by the development of a collective sense of ownership for the stressors (i.e., a "that is our problem" vs. "that is my problem" attitude), which facilitates the redefinition of difficulties as an acceptable dimension of the job ${ }^{39)}$ and stimulate a positive reappraisal of their relationship with the environment where the trauma occurred ${ }^{40)}$. Additionally, the enhanced identification with the group instils a personal sense of obligation to care about the group ${ }^{41)}$ and more positive emotions towards one's own work ${ }^{42}$. These feelings enhance perceptions of fair treatment by the surrounding environment ${ }^{43}$, which prevent avoidance thoughts about the trauma ${ }^{44)}$ and facilitate the reappraisal of the threatening event as a challenge ${ }^{45}$, thus enabling a positive conversion of PTSS into job satisfaction ${ }^{46)}$. Taken together, our line of reasoning leads us to hypothesize that the exposure to robbery moderates the relationship between PTSS and job satisfaction, such that this relationship will be positive in the case of collective (vs. individual) exposure (Hypothesis 1).

\section{Method}

\section{Participants}

This study was part of a research project on psychosocial risks that was carried out in multiple offices of a national bank in Italy. Ethical approval for this study was granted by the research ethics committee of the University of Florence (approval number 2016/168). Data were collected through a time-lagged, two-wave design, with a separation of two months between measurements. When a robbery occurred in a bank office, the staff of the bank's health and safety department proceeded to administrate the initial (Time 1) questionnaire, which assessed the exposure to robbery, PTSS and job satisfaction. Data collection took place between 48 hours and one week after the robbery. Two months later, employees who participated to the first survey were invited to respond to the second (Time 2) questionnaire, which measured job satisfaction. The questionnaires from each period were matched over time using a working identification number assigned to respondents at both Time 1 and at Time 2 . The research team obtained informed consent from all participants on written forms prior to data collection.

At Time 1,337 employees from 37 work units provided usable responses to the survey. Among them, $205 \mathrm{did}$ 
not respond or provided incomplete responses to the second survey, resulting in a sample of 132 employees with matched data across time (response rate $=39.17 \%$ ). The final sample was equally distributed between the two genders, with an average age of $41.86 \mathrm{yr}(\mathrm{SD}=9.53)$. Due to privacy-related organizational restrictions, we were not allowed to collect information about participants' organizational tenure and educational level.

\section{Measurements}

Post-traumatic stress symptoms

PTSS were measured using Giorgi et al.'s Impact of Event Scale (IES)-6 ${ }^{47)}$, which allows detecting significant PTSS among individuals exposed to traumatic events, such as robberies (e.g., "I thought about it when I didn't mean to"). The items were rated on a 5-point scale (from $1=$ not at all to $5=$ strongly). The reliability of this scale was 0.87 .

\section{Exposure to robbery}

Exposure to robbery was assessed with a dichotomous question asking each participant to indicate whether he or she had been exposed to the robbery individually (i.e., isolated exposure, coded 1) or together with other team members (i.e., shared exposure, coded 2).

\section{Job satisfaction}

Job satisfaction was assessed with the following single item developed by Giorgi et al. ${ }^{14)}$ : "How satisfied have you been with your work?". The responses were obtained on a 10 -point scale (from $0=$ no satisfaction to $10=$ satisfaction), where a higher score indicates greater job satisfaction. Single-item measures of job satisfaction have been shown to display high face validity and to be highly correlated with multiple-item measures ${ }^{48)}$. As such, they represent an acceptable and reasonable alternative to multiple-item scales.

\section{Control variable}

We controlled for gender and age, since both have been found to be related to job satisfaction ${ }^{49,50)}$. Moreover, we controlled for job satisfaction at Time 1 in order to control for the possible confounding effect of unidentified variables on the dependent variable at Time $2^{51}$.

\section{Statistical analyses}

Given the nested nature of our data, we first ran a null model with the HLM software, Version 7.01, to check whether significant between-group variance in job satisfac- tion existed. If significant between-group variance is detected, then hypotheses need to be tested using hierarchical linear modelling (HLM) analyses in order to consider the non-independence of observations ${ }^{52)}$. Specifically, we performed a $\chi^{2}$ test to examine the null hypothesis that groups were equal on job satisfaction and calculated the intra-class correlation coefficient $\left(\mathrm{ICC}_{(1)}\right)$ to estimate the degree of similarity among group members in the level of job satisfaction. Results suggested that a low degree of similarity existed among group members as only $6 \%$ of variance in scores of job satisfaction resided between groups $\left(\mathrm{ICC}_{(1)}=0.06\right)$; moreover, the $\chi^{2}$ for the grouplevel variance component was not significant $\left(\chi^{2}=41.39\right.$, $d f=34, n s$ ), which provides support for the null hypothesis that groups are equal on job satisfaction. Taken together, these results revealed non-significant between-group variability in job satisfaction), suggesting that HLM was not a suitable analytic technique. Accordingly, hypotheses were tested using multiple regression analyses in SPSS Version 22. Following Aiken and West ${ }^{53)}$, PTSS, as a continuous variable, was mean centred before entering it into regression models by subtracting the mean from the value of the original variable so that it had a mean of 0 . Mean-centring continuous variables helps prevent the multicollinearity between the main effect and the interaction variables ${ }^{53)}$. Moreover, in line with Cohen and Cohen's recommendations $^{54)}$, control variables were entered at Step 1, PTSS and exposure to robbery were entered at Step 2, and the interaction term between PTSS and exposure to robbery was introduced at Step 3. The procedure of entering the substantive study variables and the interaction term in a hierarchical manner allows determining the increment in explained variance $\left(R^{2}\right)$ that is due to the interaction term alone. In order to interpret the nature of this interaction, we performed a simple slope test by following Aiken and West's procedure ${ }^{53)}$, which implies calculating the association between the independent variable (i.e., PTSS) and the dependent variable (i.e., job satisfaction) at different values of the moderator (i.e., isolated versus vs. shared exposure to robbery). Consistent with Dawson's recommendation ${ }^{55)}$, we coded the values as 0 for isolated exposure to robbery and 1 for shared exposure to robbery to make the interpretation of the interaction effect more straightforward.

\section{Results}

Table 1 reports the descriptive statistics and correlations for all the variables. 
Table 1. Descriptive statistics and correlations

\begin{tabular}{|c|c|c|c|c|c|c|c|c|}
\hline Variables & Mean & SD & 1 & 2 & 3 & 4 & 5 & 6 \\
\hline 1. Gender ${ }^{\mathrm{a}}$ & - & - & - & & & & & \\
\hline 2. Age & 41.86 & 9.53 & $0.21^{*}$ & - & & & & \\
\hline 3. Exposure to robbery ${ }^{\mathrm{b}}$ & - & - & $-0.27^{* *}$ & -0.06 & - & & & \\
\hline 4. Post-traumatic stress symptoms & 1.44 & 0.99 & -0.15 & -0.01 & $0.17^{*}$ & $(0.87)$ & & \\
\hline 5. Job satisfaction (Time 1) & 6.49 & 1.64 & -0.10 & 0.04 & 0.03 & $-0.18^{*}$ & - & \\
\hline 6. Job satisfaction (Time 2) & 6.35 & 1.29 & -0.13 & 0.09 & 0.01 & -0.08 & $0.40^{* *}$ & - \\
\hline
\end{tabular}

${ }^{*} p<0.05 ; * *<<0.01$. SD: standard deviation.

$N=132$.

Internal consistency coefficients (Cronbach's $\alpha$ ) appear along the diagonal in parentheses.

${ }^{\mathrm{a}} \mathrm{Gender}$ is categorized in two groups: $1=$ female, $2=$ male.

${ }^{b}$ Exposure to robbery is categorized in two groups: $1=$ isolated exposure, $2=$ shared exposure.

Table 2. Results of multiple regression analyses for job satisfaction (Time 2)

\begin{tabular}{|c|c|c|c|c|c|c|}
\hline \multirow{2}{*}{ Variable/Model } & \multicolumn{2}{|c|}{ Model 1} & \multicolumn{2}{|c|}{ Model 2} & \multicolumn{2}{|c|}{ Model 3} \\
\hline & Estimate $^{\mathrm{a}}$ & SE & Estimate & SE & Estimate & SE \\
\hline \multicolumn{7}{|l|}{ Step 1} \\
\hline Gender $^{\mathrm{b}}$ & -0.28 & 0.21 & -0.30 & 0.22 & -0.31 & 0.22 \\
\hline Age & 0.01 & 0.01 & 0.01 & 0.01 & 0.02 & 0.01 \\
\hline Job satisfaction (Time 1) & $0.30^{* *}$ & 0.06 & $0.29^{* *}$ & 0.06 & $0.26^{* *}$ & 0.07 \\
\hline \multicolumn{7}{|l|}{ Step 2} \\
\hline PTSS $^{c}$ & & & -0.04 & 0.11 & $-0.32^{*}$ & 0.36 \\
\hline Exposure to robbery ${ }^{\mathrm{d}}$ & & & -0.06 & 0.22 & -0.04 & 0.21 \\
\hline \multicolumn{7}{|l|}{ Step 3} \\
\hline PTSS $\times$ Exposure to robbery & & & & & $0.50^{*}$ & 0.22 \\
\hline Total $R^{2}$ & $0.17^{* *}$ & & $0.17^{* *}$ & & $0.21^{* *}$ & \\
\hline$\Delta R^{2}$ & 484.83 & & 0.00 & & $0.04^{*}$ & \\
\hline
\end{tabular}

$* p<0.05 ; * * p<0.01$. SE: standard error.

$N=132$.

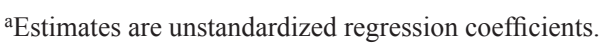

${ }^{b}$ Gender is categorized in two groups: $1=$ female, $2=$ male.

'PTSS $=$ post-traumatic stress symptoms.

dExposure to robbery is categorized in two groups: $1=$ isolated exposure, $2=$ shared exposure.

Hypothesis 1 suggested that exposure to robbery would moderate the relationship between PTSS and job satisfaction. As shown in Table 2, multiple regression analyses revealed that, at Step 1, of the control variables only gender was a significant predictor for job satisfaction at $\mathrm{T} 2$ $(\beta=0.26, p<0.01)$. At Step 2, PTSS negatively and significantly predicted job satisfaction at T2 $(\beta=-0.32, p<0.05)$. At Step 3, PTSS significantly interacted with exposure to robbery in predicting job satisfaction $(\beta=0.50, p<0.05$, Model 3).

This interaction is graphically represented in Fig. 1. Results from the simple slope test showed that the relationship between PTSS and job satisfaction was not significant in the case of isolated exposure to robbery $(\beta=0.18, n s)$, but became significantly positive in the case of shared exposure $(\beta=0.67, p<0.05)$. Thus, these results support Hypothesis 1.

\section{Discussion}

The present study aimed to clarify the conditions under which PTSS following a bank robbery could be a driver of - rather than a threat to-employee job satisfaction. Consistent with our Hypothesis, our findings provided empirical evidence for the moderating effect of exposure to robbery on the relationship between PTSS and job satisfaction: this relationship was positive and significant in the case of shared exposure but turned to non-significant 


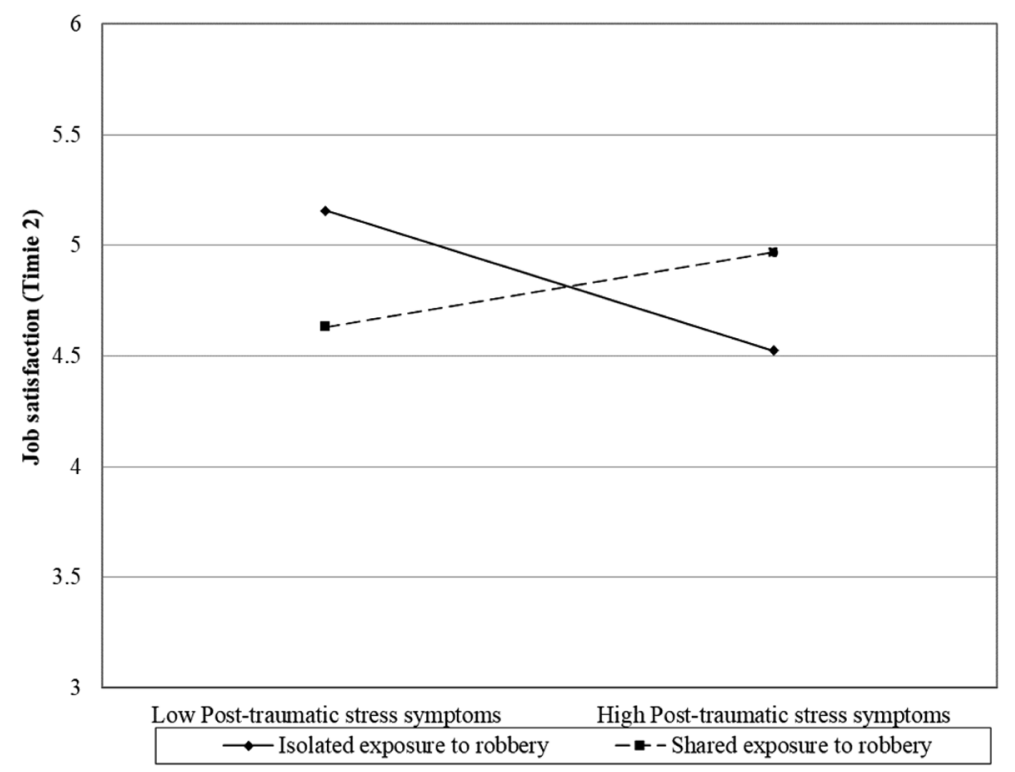

Fig. 1. Moderating effect of exposure to robbery on the relationship between post-traumatic stress symptoms and job satisfaction. For isolated exposure to robbery, $\beta=0.18$, ns. For shared exposure to robbery, $\beta=0.67, p<0.05$.

in the case of isolated exposure. Interestingly, unlike prior research documenting the detrimental impact of PTSS on job satisfaction, our findings suggest that this relationship is more complex and context dependent. Indeed, we found that PTSS did not predict job satisfaction independently, but only in interaction with the exposure to robbery. Accordingly, our investigation provides a unique contribution to the existing literature on psychological sequelae following robbery exposure. While previous studies have shown the negative consequences of PTSS on job satisfaction $^{56)}$, the buffering conditions under which such effects might change remain largely unexplored. We extend this research stream to show that individuals with high PTSS who experienced the trauma collectively reported greater job satisfaction levels in comparison with those with low PTSS.

This way, we highlight the relevance of integrating the assumptions implied in the COR framework ${ }^{16,17)}$ with the insights from the PTG literature to understand the key role of social factors (i.e., shared exposure to robbery) in shaping the relationship between PTSS and job satisfaction. The COR theory ${ }^{16,17)}$, by emphasizing conservation strategies for the mobilization and acquisition of new resources, may help explain how individuals suffering from PTSS can experience a PTG in terms of job satisfaction. On its part, the PTG literature clarifies what specific conditions (i.e., collective exposure to the trauma) are necessary to enable individuals to undertake such conservation strate- gies and, thereby, achieve an improved psychological functioning following the traumatic experience. To the best of our knowledge, prior to our research, Hochwarter and colleagues' study ${ }^{57)}$ was the only one that empirically documented the role of perceived resources in positively shaping the relationship between trauma-related stress and job satisfaction. Additionally, we measured job satisfaction immediately after the robbery and two months later. Only a few trauma studies have assessed job satisfaction, though it represents an important pre-trauma risk factor. Indeed, job satisfaction was found to significantly predict post-event satisfaction one year later, over and above the trauma exposure itself ${ }^{58)}$. Our investigation goes an important step further by clarifying for the first time the boundary conditions that allow people to access the resources necessary to experience positive outcomes (e.g., job satisfaction) despite the development of PTSS. In doing so, this research also enhances our understanding of the resource gains associated with exposure to traumatic events, highlighting the shared, rather than individual, nature of the trauma as a key condition upon which people can access the resources necessary to achieve such gains.

However, the findings are also subjected to some limitations. First, this study relied on one source of information for data gathering, which might contribute to common method bias ${ }^{59)}$. Yet, this risk is reduced by adopting a twowave design and by including the dependent variable (i.e., job satisfaction) as control at Time 1. It should be noted 
that, according to COR theory ${ }^{16,17)}$, resource losses following a traumatic experience lead to high initial PTSS levels, but PTG may serve as a kind of resource caravans which supports individuals to recover over time ${ }^{22)}$. In this view, it might be possible that PTSS and PTG would be positively intercorrelated soon after PTEs, but negatively correlated later in time ${ }^{22)}$. Therefore, future studies should consider longer period of separation between measures to shed light on these relationships. Second, except for the exposure to robbery, data on pre- and other peri-traumatic risk factors, which may influence workers' susceptibility to PTSS $^{60)}$, were not collected. Consequently, further studies should control for these confounding variables (e.g., prior trauma history). Third, results may not be generalizable to other working populations, since they were based on the banking context. Replications should thus be conducted in other professional contexts through replication studies. Fourth, although these findings emphasize the importance of social resources in transmitting the moderating effects of the collective exposure (i.e., social support, group identification), this study did not include measures of such resources. Likewise, we did not assess PTG (e.g., cognitive reappraisal) and COR (e.g., acquisition of new resources) processes through which PTSS may stimulate increased job satisfaction. Future studies should hence include these variables to develop and test more complex moderated mediation models that would help understand how and when PTSS following traumatic exposure can lead to improved psychological functioning at work. Finally, since the purpose of the study was to detect post-traumatic stress symptomatology without making a diagnosis of post-traumatic stress disorders (PTSD), we used the wellknown, validated IES scale ${ }^{47}$. This measure embraces criteria for PTSD as defined by DSM-IV ${ }^{61)}$ and showed good reliability in the present study. However, in order to make a more comprehensive diagnosis of post-traumatic stress symptoms, it would be useful to include clinical examinations in future studies. Moreover, more research is needed to better understand the relationship between job satisfaction levels following PTEs at work and the overall level of life satisfaction among affected workers. For instance, future studies could analyse whether, under circumstances of work-life balance, job satisfaction following shared exposure to work PTEs would be positively associated with satisfaction in other life domains. Moreover, more research is needed to analyse the impact of work-related PTEs on different life areas. Indeed, the finding that positive results (i.e., greater PTG in terms of job satisfaction) following PTEs may co-occur with high PTSS (when the trauma is collectively shared) could suggest that reduced functioning in some life domains (e.g., social functioning) can happen despite the increased functioning in a specific area (e.g., the work-related domain).

From a practical standpoint, our results suggest that employees suffering from PTSS following a collective exposure to a traumatic event might derive benefits from group-level interventions to improve their psychological functioning at work. Such interventions should enhance supportive actions within the team and promote an increased sense of group identification to allow victims to experience a positive change from the trauma. Companies should supply organizational resources and promote resource gain climates by implementing training programs that foster passageways for social resource caravans, enhancing effective internal communication, encouraging bounding among group members, and improving morale, cooperation, and collective coping skills within the team $^{62)}$. Furthermore, organizations could provide their employees with training on team resilience (i.e., "a team's belief that it can absorb and cope with strain, as well as a team's capacity to cope, recover and adjust positively to difficulties", p.149) ${ }^{63)}$, which is focused on collective resilient characteristics, such as collective efficacy, team cohesion and team adaptability ${ }^{64)}$. These skills can be strengthened by key psychosocial conditions, including team learning, social identity, positive emotions, transformational leadership and shared leadership ${ }^{65)}$. For instance, in order to foster the resilience of team members, companies could consider training team leaders to enact transformational behaviours, such as seeking team members' ideas about how to handle critical events and encouraging them to ask for assistance when needed ${ }^{66)}$. Likewise, group treatments for PTSS (e.g., group psychological debriefing) can be realized to facilitate protected settings in which victims can engage in group sharing and collaborative processes $^{67)}$.

\section{Conclusion}

In conclusion, this study demonstrates that PTSS is not always bad for employee positive functioning in the workplace. Precisely, our results suggest that when a traumatic event is experienced collectively, rather than in isolation, employees with high levels of PTSS, as opposed to those with low levels of PTSS can benefit from the shared nature of the trauma to undergo a post-traumatic growth that allows them to be ultimately more satisfied with their job. These findings highlight that, in the case of 
collective exposure to a traumatic event, it is essential to direct occupational health interventions towards the group itself in order to enable the victims of trauma to access the necessary social resources to improve their psychological functioning.

\section{Conflict of Interest}

The authors declare that they do not have any conflict of interest with this paper.

\section{References}

1) European Bank Federation Bank robberies. EBF security report. https://www.ebf.eu/strategic-themes-copy/bankrobberies/. Accessed June 10, 2019.

2) Monnier J, Cameron RP, Hobfoll SE, Gribble JR (2002) The impact of resource loss and critical incidents on psychological functioning in fire-emergency workers: a pilot study. Int J Stress Manag 9, 11-29. [CrossRef]

3) Belleville G, Marchand A, St-Hilaire MH, Martin M, Silva C (2012) PTSD and depression following armed robbery: patterns of appearance and impact on absenteeism and use of health care services. J Trauma Stress 25, 465-8. [Medline] [CrossRef]

4) American Psychiatric Association (2013) Diagnostic and statistical manual of mental disorders (DSM- $5^{\circledR}$ ). American Psychiatric Pub, Washington DC.

5) DeFraia GS (2015) Psychological trauma in the workplace: variation of incident severity among industry settings and between recurring vs. isolated incidents. Int J Occup Environ Med 6, 155-68. [Medline] [CrossRef]

6) Smith SM, Vela E (2001) Environmental context-dependent memory: a review and meta-analysis. Psychon Bull Rev 8, 203-20. [Medline] [CrossRef]

7) VandePol R, Beyer CE (2009) Crisis management: the critical human element. CMFA-Building Profits 27, 10-7.

8) Gustavsson A, Svensson M, Jacobi F, Allgulander C, Alonso J, Beghi E, Dodel R, Ekman M, Faravelli C, Fratiglioni L, Gannon B, Jones DH, Jennum P, Jordanova A, Jönsson L, Karampampa K, Knapp M, Kobelt G, Kurth T, Lieb R, Linde M, Ljungcrantz C, Maercker A, Melin B, Moscarelli M, Musayev A, Norwood F, Preisig M, Pugliatti M, Rehm J, Salvador-Carulla L, Schlehofer B, Simon R, Steinhausen HC, Stovner LJ, Vallat JM, Van den Bergh P, van Os J, Vos P, Xu W, Wittchen HU, Jönsson B, Olesen J, CDBE2010Study Group (2011) Cost of disorders of the brain in Europe 2010. Eur Neuropsychopharmacol 21, 718-79. [Medline] [CrossRef]

9) Duan W, Guo P, Gan P (2015) Relationships among trait resilience, virtues, post-traumatic stress disorder, and posttraumatic growth. PLoS One 10, e0125707. [Medline] [CrossRef]
10) Tedeschi RG, Calhoun LG (2004) Posttraumatic growth: conceptual foundations and empirical evidence. Psychol Inq 15, 1-18. [CrossRef]

11) Setti I, Argentero P (2016) Traumatization and PTSD in rescue workers: prevention, assessment, and interventions. In: Comprehensive Guide to Post-Traumatic Stress Disorder, Martin CR, Preedy VR, Patel VB (Eds.),1-13, Springer International Publishing, Basel.

12) Helgeson VS, Reynolds KA, Tomich PL (2006) A metaanalytic review of benefit finding and growth. J Consult Clin Psychol 74, 797-816. [Medline] [CrossRef]

13) Alexopoulos EC, Palatsidi V, Tigani X, Darviri C (2014) Exploring stress levels, job satisfaction, and quality of life in a sample of police officers in Greece. Saf Health Work 5, 210-5. [Medline] [CrossRef]

14) Giorgi G, Leon Perez JM, Montani F, Courcy F, Arcangeli G (2015) Distress and job satisfaction after robbery assaults: a longitudinal study. Occup Med (Lond) 65, 290-5. [Medline] [CrossRef]

15) Vinokur AD, Pierce PF, Lewandowski-Romps L, Hobfoll SE, Galea S (2011) Effects of war exposure on air force personnel's mental health, job burnout and other organizational related outcomes. J Occup Health Psychol 16, 3-17. [Medline] [CrossRef]

16) Hobfoll SE (1989) Conservation of resources. A new attempt at conceptualizing stress. Am Psychol 44, 513-24. [Medline] [CrossRef]

17) Hobfoll SE (2001) The influence of culture, community, and the nested-self in the stress process: advancing conservation of resources theory. Appl Psychol 50, 337-421. [CrossRef]

18) Setti I, van der Velden PG, Sommovigo V, Ferretti MS, Giorgi G, O'Shea D, Argentero P (2018) Well-being and functioning at work following thefts and robberies: a comparative study. Front Psychol 9, 168. [Medline] [CrossRef]

19) Sommovigo V, Setti I, O'Shea D, Argentero P (2018) Victimization on the job: the influence of thefts and robberies on Irish and Italian employees and its relationship with psychological well-being. Int J Cult Ment Health 11, 653-66. [CrossRef]

20) Gerhart JI, Canetti D, Hobfoll SE (2015) Traumatic stress in overview: definition, context, scope, and long-term outcomes. In: Traumatic Stress and Long-Term Recovery, Cherry KE (Ed.), 3-24, Springer, New York.

21) Hobfoll SE, Halbesleben J, Neveu JP, Westman M (2018) Conservation of resources in the organizational context: the reality of resources and their consequences. Annu Rev Org Psychol Organ Behav 5, 103-28. [CrossRef]

22) Zalta AK, Gerhart J, Hall BJ, Rajan KB, Vechiu C, Canetti D, Hobfoll SE (2017) Self-reported posttraumatic growth predicts greater subsequent posttraumatic stress amidst war and terrorism. Anxiety Stress Coping 30, 176-87. [Medline] [CrossRef]

23) Hobfoll SE (2012) Conservation of resources and disaster 
in cultural context: the caravans and passageways for resources. Psychiatry 75, 227-32. [Medline] [CrossRef]

24) Halbesleben JRB, Bowler WM (2007) Emotional exhaustion and job performance: the mediating role of motivation. J Appl Psychol 92, 93-106. [Medline] [CrossRef]

25) Tedeschi RG, Park CL, Calhoun LG (1998) Posttraumatic growth: positive changes in the aftermath of crisis. Lawrence Erlbaum Associates, Hillsdale.

26) Zoellner T, Maercker A (2006) Posttraumatic growth in clinical psychology - a critical review and introduction of a two component model. Clin Psychol Rev 26, 626-53. [Medline] [CrossRef]

27) Hobfoll SE, Hall BJ, Canetti-Nisim D, Galea S, Johnson RJ, Palmieri PA (2007) Refining our understanding of traumatic growth in the face of terrorism: Moving from meaning cognitions to doing what is meaningful. Appl Psychol 56, 345-66. [CrossRef]

28) Laufer A, Solomon $Z$ (2006) Posttraumatic symptoms and posttraumatic growth among Israeli youth exposed to terror incidents. J Soc Clin Psychol 25, 429-47. [CrossRef]

29) Shechory Bitton M, Laufer A (2017) PTSD and PTG among Israeli mothers: opposite facets of exposure to terrorism. Stress Health 33, 676-83. [Medline] [CrossRef]

30) Páez D, Basabe N, Ubillos S, González-Castro JL (2007) Social sharing, participation in demonstrations, emotional climate, and coping with collective violence after the march 11th Madrid bombings. J Soc Issues 63, 233-337. [CrossRef]

31) Vázquez C, Pérez-Sales P, Hervás G (2008) Positive effects of terrorism and posttraumatic growth: an individual and community perspective. In: Trauma, recovery, and growth: positive psychological perspectives on posttraumatic stress, Joseph S and Linley PA (Eds.), 63-91, Wiley, Hoboken.

32) Tsai J, El-Gabalawy R, Sledge WH, Southwick SM, Pietrzak RH (2015) Post-traumatic growth among veterans in the USA: results from the National Health and Resilience in Veterans Study. Psychol Med 45, 165-79. [Medline] [CrossRef]

33) Grad RI, Zeligman M (2017) Predictors of post-traumatic growth: the role of socialinterest and meaning in life. SA J Ind Psychol 73, 190-207.

34) Rimé B, Páez D, Basabe N, Martínez F (2010) Social sharing of emotion, post-traumatic growth, and emotional climate: follow-up of Spanish citizen's response to the collective trauma of March 11th terrorist attacks in Madrid. Eur J Soc Psychol 40, 1029-45. [CrossRef]

35) Yildiz AA, Verkuyten M (2011) Inclusive victimhood: social identity and the politicization of collective trauma among Turkey's Alevis in Western Europe. Peace Conflict 17, 243-69. [CrossRef]

36) Pagliaro S, Alparone FR, Picconi L, Paolini D, Aquino A (2013) Group based resiliency: contrasting the negative effects of threat to the ingroup. Curr Res Soc Psychol 21, $35-41$.
37) Schwarzer R, Knoll N (2007) Functional roles of social support within the stress and coping process: a theoretical and empirical overview. Int J Psychol 42, 243-52. [CrossRef]

38) Prati G, Pietrantoni L (2009) Optimism, social support, and coping strategies as factors contributing to posttraumatic growth: a meta-analysis. J Loss Trauma 14, 364-88. [CrossRef]

39) Loriol M (2016) Collective forms of coping and the social construction of work stress among industrial workers and police officers in France. Theory Psychol 26, 112-29. [CrossRef]

40) Lazarus RS (1994) Psychological stress in the workplace. In: Occupational stress: a handbook, Crandall R and Perrewé PL (Eds.), Taylor and Francis, New York.

41) Hogg MA, Terry DJ, White KM (1995) A tale of two theories: a critical comparison of identity theory with social identity theory. Soc Psychol Q 58, 255-69. [CrossRef]

42) van Dick R, Schuh SC (2010) My boss' group is my group: experimental evidence for the leader-follower identity transfer. Leadersh Organ Dev J 31, 551-63. [CrossRef]

43) Stel M, van den Bos K, Sim S, Rispens S (2013) Mimicry and just world beliefs: mimicking makes men view the world as more personally just. Br J Soc Psychol 52, 397-411. [Medline] [CrossRef]

44) Zellars KL, Liu Y, Bratton V, Brymer R, Perrewé P (2004) An examination of the dysfunctional consequences of organizational injustice and escapist coping. J Manag Issue 16, 528-44.

45) Lerner MJ, Miller NH (1978) Just world research and the attribution process: looking back and ahead. Psychol Bull 85, 1030-51. [CrossRef]

46) Webster JR, Beehr TA, Love K (2011) Extending the challenge-hindrance model of occupational stress: the role of appraisal. J Vocat Behav 79, 505-16. [CrossRef]

47) Giorgi G, Fiz Perez FS, Castiello D’Antonio A, Mucci N, Ferrero C, Cupelli V, Arcangeli G (2015) Psychometric properties of the Impact of Event Scale-6 in a sample of victims of bank robbery. Psychol Res Behav Manag 8, 99-104. [Medline] [CrossRef]

48) Nagy MS (2002) Using a single-item approach to measure facet job satisfaction. J Occup Organ Psychol 75, 77-86. [CrossRef]

49) Brush DH, Mock MK, Pooyan A (1987) Individual demographic differences and job satisfaction. J Organ Behav 8, 139-55. [CrossRef]

50) Oshagbemi T (2000) Satisfaction with co-workers' behaviour. Employee Relat 22, 88-106. [CrossRef]

51) Cole DA, Maxwell SE (2003) Testing mediational models with longitudinal data: questions and tips in the use of structural equation modeling. J Abnorm Psychol 112, 558-77. [Medline] [CrossRef]

52) Raudenbush SW, Bryk AS (2002) Hierarchical linear models: applications and data analysis methods. Sage, Newbury Park. 
53) Aiken LS, West SG (1991) Multiple regression: testing and interpreting interactions. Sage, Newbury Park.

54) Cohen J, Cohen P (1983) Applied multiple regression/ correlation analysis for the behavioral sciences, 2nd Ed., Erlbaum, Hillsdale.

55) Dawson JF (2014) Moderation in management research: what, why, when, and how. J Bus Psychol 29, 1-19. [CrossRef]

56) Dekel R, Hobfoll SE (2007) The impact of resource loss on Holocaust survivors facing war and terrorism in Israel. Aging Ment Health 11, 159-67. [Medline] [CrossRef]

57) Hochwarter WA, Laird MD, Brouer RL (2008) Board up the windows: the interactive effects of hurricane-induced job stress and perceived resources on work outcomes. J Manage 34, 263-89.

58) van der Velden PG, Setti I, Bosmans MWG, Muffels RJA (2018) Potentially traumatic events and job satisfaction. A prospective population-based comparative study. J Occup Environ Med 60, e126-33. [Medline] [CrossRef]

59) Podsakoff PM, MacKenzie SB, Podsakoff NP (2012) Sources of method bias in social science research and recommendations on how to control it. Annu Rev Psychol 63, 539-69. [Medline] [CrossRef]

60) Ozer EJ, Best SR, Lipsey TL, Weiss DS (2003) Predictors of posttraumatic stress disorder and symptoms in adults: a meta-analysis. Psychol Bull 129, 52-73. [Medline] [CrossRef]
61) Segal DL (2010) Diagnostic and statistical manual of mental disorders (DSM-IV-TR), 1-3, The Corsini Encyclopedia of Psychology, Washington.

62) Chen S, Westman M, Hobfoll SE (2015) The commerce and crossover of resources: resource conservation in the service of resilience. Stress Health 31, 95-105. [Medline] [CrossRef]

63) Carmeli A, Friedman Y, Tishler A (2013) Cultivating a resilient top management team: the importance of relational connections and strategic decision comprehensiveness. Saf Sci 51, 148-59. [CrossRef]

64) Morgan PB, Fletcher D, Sarkar M (2013) Defining and characterizing team resilience in elite sport. Psychol Sport Exerc 14, 549-59. [CrossRef]

65) Morgan PB, Fletcher D, Sarkar M (2015) Understanding team resilience in the world's best athletes: a case study of a rugby union World Cup winning team. Psychol Sport Exerc 16, 91-100. [CrossRef]

66) Dvir T, Eden D, Avolio BJ, Shamir B (2002) Impact of transformational leadership on follower development and performance: a field experiment. Acad Manage J 45, 735-44.

67) Ellis CC, Peterson M, Bufford R, Benson J (2014) The importance of group cohesion in inpatient treatment of combat-related PTSD. Int J Group Psychother 64, 208-26. [Medline] [CrossRef] 